\title{
Dental professionalism: definitions and debate
}

\author{
A. Trathen ${ }^{1}$ and J. E. Gallagher ${ }^{2}$
}
- Highlights an important issue for the whole profession.
- Informs colleagues of the debate amongst our medical counterparts.
- Stimulates debate and possibly future action.

\begin{abstract}
Professionalism has been identified as a core component of revalidation by the General Dental Council.' However, analysis and debate over what it means to be a professional dentist is lacking in modern dentistry in the United Kingdom. The aim of this article is to open a debate on concepts of professionalism within dentistry, drawing on established thoughts in medicine and more limited material from the dental domain. The scope of discussion will extend to include definitions of professionalism, ethical issues within professionalism, professionalism in relation to revalidation and where all of these issues relate to dentistry perceived as a business. We can learn much from the medical community who have been driven to consider 'medical professionalism in a changing world', ${ }^{2}$ and in support of 'better patient care.'. However, we can also contribute to the wider debate on professionalism by tackling the business angle, which has been largely ignored by our medical counterparts, and adding greater weight to the ethical implications of being a professional.
\end{abstract}

\section{WHAT CONSTITUTES DENTAL PROFESSIONALISM?}

Professionalism is a word of which we feel we have an intuitive understanding. From the earliest years of our training we are told that it is important to uphold professional standards. 'Be professional' is such a versatile ethical imperative that it can give guidance in how we ought to act in almost all aspects of our working lives. Professionalism is soon to become a quantified measure of our fitness to continue practice. Yet despite this ubiquitous idea of professionalism, there is as yet no commonly agreed definition of the word, and trying to get to the meaning behind it is a mammoth philosophical endeavour.

Professionalism within medicine has recently been looked at in great depth. ${ }^{2-4}$

\footnotetext{
'Senior House Officer in Dental Public Health, King's College Hospital, Denmark Hill, London, SE5 9RW;

${ }^{2 *}$ King's College London Dental Institute, Head of Oral

Health Services Research \& Dental Public Health, Senior Lecturer/Honorary Consultant in Dental Public Health. Denmark Hill Campus, Caldecot Road, London, SE5 9RW ${ }^{*}$ Correspondence to: Dr Jenny Gallagher

Email: jenny.gallagher@kcl.ac.uk
}

\section{Refereed Pape}

Accepted 14 January 2009

DOI: 10.1038/sj.bdj.2009.164

${ }^{\circ}$ British Dental Journal 2009; 206: 249-253
A key impetus for this has been the role of the doctor in a changing social and political background, ${ }^{2}$ leading to changes in expectation that patients, the public, managers and the Government show towards medical practitioners, ${ }^{4}$ as well as the challenges of working in healthcare teams where the role of the doctor is increasingly less well defined. ${ }^{4}$ The work to date has involved a Royal College of Physicians (RCP) Working Party which took wide ranging evidence and commissioned further research, ${ }^{2}$ seminars, ${ }^{3}$ and subsequent road shows to explore the harnessing of professionalism. ${ }^{4}$

Dentists have also been influenced by these socio-political changes, despite arriving at their current professional status via a somewhat different journey. Historically dentistry has followed the path of barber-surgeons, beginning as mainly a business enterprise in the late nineteenth and twentieth centuries, ${ }^{5}$ and later moving to a model more analogous to that of the medical profession. Dentistry eventually came to be recognised as a true profession that had a 'social contract' with the public.

As consumerist culture has become more prevalent, Welie ${ }^{6}$ suggests that dentistry is increasingly moving back toward the business model. This rings particularly true for dental cosmetic procedures in the private arena - benefits to the patient may be purely aesthetic and the practitioner must strike the correct balance between satisfying the demands of the patient and maintaining professional standards of appropriate treatment, often in the shadow of powerful financial incentives. Plastic surgeons face similar issues, and much of their work is also performed in the private sector. Foundation Trusts have significant business incentives in the English NHS. It seems clear that any meaningful discussion of professionalism and ethics must necessarily consider the implications that business and economics has on the services we provide.

Our medical profession has not yet addressed this 'business element' of healthcare beyond resource allocation with regard to patients, despite the fact that many consultants run a successful private practice in parallel with their hospital commitments. The business element may be more conspicuous in dentistry because much of dentistry undertaken involves patients' paying direct charges. This will however become an increasingly important issue 
for doctors as co-payments for expensive cancer drugs become acceptable as part of NHS care. ${ }^{?}$

Over recent years, a relatively small number of well-publicised serious failures have understandably eroded public faith in the principle of self-regulation, once considered to be a defining characteristic of a professional. In dentistry, news stories of rogue dentists practising illegally and unethically do much to undermine the vast majority of the profession who do practise legally, ethically, and with a sincere wish to do what is best for their patients (though there have been proponents of the idea that the ideal of altruism is never fully realised in healthcare professions). ${ }^{8}$ There is now a greater demand for assurance against the risk of encountering a malpractising dentist.

The GDC is already moving to address this changing demand on dentists by introducing the five-year revalidation process, ${ }^{1}$ following our medical counterparts. A dentist will need to demonstrate their suitability for revalidation in four key domains, one of which is 'professionalism'. The revalidation assessment '...would need to be sufficiently robust to justify removal from the register in the event of a registrant failing to demonstrate fitness. ${ }^{9}$

If professionalism is going to form 25\% of an assessment of such gravity that it justifies removal from the register, it stands to reason that all parties involved should have a very clear understanding of what professionalism actually is. We are some distance from achieving this, and quite conceivably may never come to a universal consensus, but it is clear that at the very least we have an obligation to open dialectic and give the meaning of professionalism some serious thought.

\section{DEFINITIONS OF PROFESSIONALISM}

From the selection of definitions outlined in Figure 1, we see two broad themes. Masella, ${ }^{10}$ Welie, ${ }^{11}$ Nath, ${ }^{12}$ and AIBM et $a l .{ }^{13}$ are similar in that they purport the idea of putting the needs of others first. Mixed into this core theme we see ideas of a high level of skill, commitment to the cause, and trust from the public.

The Brosky definition ${ }^{14}$ focuses more on the building of a relationship with the patient, again touching on issues of trust and reliability. This is very much the core theme of the RCP, ${ }^{2}$ and Nath, ${ }^{12}$ ABIM et al. ${ }^{13}$ definitions which recognise the changing dynamic away from paternalism towards involving the patient in decision making.

The RCP definition and description, ${ }^{2}$ although devised primarily for the medical profession, can be applied almost without modification to the practice of dentistry. This is attributable to two factors: firstly, the clarity and care with which they have been formulated, and secondly, the fact that most of the commitments are based on ethical principles widely valued in our society regardless of the professional status of the individual. Integrity and compassion are certainly not monopolised by the medical and dental professions. They are ethical ideals that in our society are internalised from a young age, and the RCP commitments merely make explicit a number of general moral principles they have deemed most relevant to the pursuit of professionalism.

The RCP report discusses issues of self-regulation and autonomy, once considered key criteria to defining a professional. Whilst acknowledging that autonomy can bring freedom from interference by patient interests, the RCP take a stark view of self-regulation: '[It] is irrelevant to the essential values and behaviours that underpin professional practice.' This is certainly echoed by the forthcoming changes to the GDC. Self-regulation as a profession is out, as with the new GDC we will be heavily lay regulated.

It is possible though that this proscription of self-regulation to professional practice may be a little too strong, as on an individual level an ethically driven, self-regulated, sustained effort to improve quality of care seems very likely to bring results, maybe more so than external lay forces. A clear example of individual self-regulation comes in the form of appraisal. Appraisals are formative, developmental and confidential, ${ }^{15}$ and allow reflection on one's own practice. The process of appraisal and CPD, when well executed, correlates with improved clinical outcomes. ${ }^{16}$ Self-regulation may still have a place then, but in an attenuated and personalised form; certainly no longer on a profession-wide scale.

\section{ETHICS AND PROFESSIONALISM}

The strong ethical themes from the definitions in Figure 1 are important. Professionalism is a concept that informs how we ought to act, and as such belongs firmly in the realm of ethics. Ideas of how we must act serve as a counterpoint to this. What we must do is set out in regulation and law. This is an important distinction; the compulsion to act morally is driven from an internalised set of moral rules, and can in all meaningful ways be considered voluntary. It is an 'ought' action. The compulsion to act legally is driven by the threat of sanction and punishment. This is the 'must' action.

Both components are vital to give the dental profession guidance, and although both will influence many decisions we take they do have differing roles. Within the context of dentistry, the 'must' represents a decision taken on minimum standards that dentists are expected to achieve, for the safety of their patients, their staff, and themselves. The 'ought' represents the constant attempt to achieve more than is required: to realise our potentials. This is a concept which gets to the heart of professionalism striving for the best when there are no external forces compelling you to do so.

It follows from this that we can expect 'must'-type regulations to be easy to formalise, rules that can be agreed upon and enforced. The 'ought' is far harder to formalise in this way as it is dependent upon the individual. We can thus see perhaps why professionalism is not an easy word to define.

The obvious difficulty with such a nebulous concept as professionalism is that if there is no obligation to strive for professional ideals, there will always be a minority who flout these ideals to such an extent that they may place patients and colleagues at risk of harm. Leaving professions to be fully self-regulated in the past has led to spectacular professional failures, ${ }^{17}$ and the changing demands of the public, ${ }^{3}$ bring into focus the need to both strengthen the 'must' in professional practice, and to discourage 


\section{Brosky, 2003}

We define professionalism in its broadest sense as an image that promotes a successful relationship with the patient. This relationship would be one in which the patient feels confident in the capabilities of the health care provider.

\section{Masella, 2007}

[Professionalism is] a life characterized by display of high intellectual, technical, and moral qualities and abilities, in service to patients and community.

\section{Nath et al., 2005}

Higher professionalism may be defined as a service that transcends self-interest and manifests when the task is poorly defined, solutions are not available or affordable and rendering service is not in one's own best financial, social, or physical interest.

\section{Welie, 2004}

[A profession is a] collective of expert service providers who have jointly and publicly committed to always give priority to the existential needs and interests of the public they serve above their own and who in turn are trusted by the public to do so.

\section{Royal College of Physicians, 2005}

Medical professionalism signifies a set of values, behaviours and relationships that underpins the trust the public has in doctors.

Supplemented by a description:

Medicine is a vocation in which a doctor's knowledge, clinical skills, and judgement are put in the service of protecting and restoring human well-being. This purpose is realised through a partnership between patient and doctor, one based on mutual respect, individual responsibility, and appropriate accountability. In their day-to-day practice, doctors are committed to:

- Integrity

- Compassion

- Altruism

- Continuous improvement

- Excellence

- Working in partnership with members of the wider healthcare team.

These values, which underpin the science and practice of medicine, form the basis for a moral contract between the medical profession and society. Each party has a duty to work to strengthen the system of healthcare on which our collective human dignity depends.

A Physician Charter, 2002 (Project of the ABIM Foundation, ACP-ASIM Foundation,
and European Federation of Internal Medicine, 2002)
Professionalism is the basis of medicine's contract with society.
Fundamental Principles
- Primacy of patient welfare
- Patient autonomy
- Social justice.
Set of professional responsibilities involving a commitment to:
1. Professional competence
2. Honesty with patients
3. Patient confidentiality
4. Maintaining appropriate relations with patients
5. Improving quality care
6. Improving access to care
7. A just distribution of finite resources
8. Scientific knowledge
9. Maintaining trust by managing conflicts of interest
10. Professional responsibilities.

Fig. 1 Definitions of professionalism

individuals lacking the 'ought' from entering the profession to begin with.

Revalidation can be seen as an attempt to allay the public fears that their trust in the professionalism of dentistry is no longer justified, and its aim is to 'create a conspicuous, effective regulatory framework which assures the public of a minimum standard to be expected from dentists'. ${ }^{18}$ Revalidation is a proposed solution to monitor those "ethicallyimpaired' dentists who do not exhibit the characteristics of altruism, striving for excellence etc, that seem so tied up in what we consider professionalism to be.

\section{REVALIDATION}

Revalidation represents a shift from 'ought' to 'must'. Issues which were once considered to be left to the discretion of the practitioner will now be formally assessed, and registrants must demonstrate satisfactory standards under four domains: clinical, communication, management and leadership, and professionalism. Appraisal and CPD will appropriately form the core of the revalidation candidate's portfolio, and although this will for many practitioners be a new feature of working life, it will hopefully encourage dentists to challenge themselves and reignite those aspects of professionalism which drive up standards of patient care.

Going through the five-year cycle should thus bring improvements to all facets of the dentist's practice. However, we should not forget that the ultimate purpose of revalidation is to bring into force punitive measures for those members of the dental profession who fail to meet the minimum standards and assure the public that no rogues will be able to threaten them. Revalidation is not yet well enough established to have provided evidence of its efficacy, but it certainly provides a logical and practicable attempt to bring in measures that further the public interest, in both perception and reality.

'The objective of revalidation is to reassure patients and public that dental professionals regularly demonstrate that they meet a satisfactory standard to stay on the GDC's registers'. ${ }^{18}$

We must hope then that once matured and brought into effect, the revalidation process will strike the correct balance between giving dentists the freedom to use their own ethical drive towards professionalism, while bringing into force minimum 'must' standards that will protect the public from the unprofessional minority. The GDC do recognise that autonomy is required, and that it is not appropriate for them to set standards for all possible circumstances. ${ }^{19}$ This recognition will hopefully ensure that the ethical drive is not stifled, mitigating the dangers of fostering an attitude of 'I've reached the "satisfactory standard", why do more?'

An unfortunate truth of nearly any regulatory framework is the fact that it will always be possible for a determined, deceptive individual to evade detection. Regulation can never provide an adequate substitute for a trustworthy dentist ${ }^{10}$ who holds true to the ideals we have already mentioned. A pressing question currently is whether 
we can separate the virtuous from the decadent at the level of undergraduate entry, preventing the less-trustworthy from ever claiming a place in our profession at all.

\section{PROFESSIONALISM - INNATE OR LEARNT?}

Is it possible for us to instil professional values into an individual? If not, can we identify the most promising candidates in terms of values and personality? There is limited research in the field but one study involving a convenience sample of medical and dental students suggested that dental students were less altruistic than their medical counterparts. Crossley and Mubarik ${ }^{20}$ suggested that dental students were significantly more likely to be motivated by 'status and security', 'high income' and the 'nature of the occupation', when compared with doctors, whereas medical students were significantly more likely to be motivated by 'altruism' than dental students. Further research is required to validate these findings which if true, are a matter of concern.

The recent implementation of the United Kingdom Clinical Aptitude Test (UKCAT), ${ }^{21}$ currently being trialled by many UK medical and dental schools, appears to be driven by the view that professionalism is innate and the desire to select students on the basis of professional characteristics, rather than merely academic standards. The exam is not without controversy, and significant debate is being held over the validity and limited evidence base.

There have been suggestions that by using more individualised admissions systems, certain personality traits can be screened for that correlate to greater professional competence after training. ${ }^{22}$ This may or may not be captured by UKCAT or equivalent tests, but the trend towards looking at medical and dental applicants in terms of who they are, rather than simply what they have accomplished academically appears rational to an increasing number of people.

Mathewson and Rudkin $^{19}$ raise an important issue. They question the feasibility of relying on a shared ideal of professionalism when there is so much variation in age, culture and education between dentists. We would suggest the very fact that twenty-first century Britain possesses such a pluralistic understanding of values and cultures is a powerful incentive for us to create an explicit professional ideal, one that spans the differences and captures the similarities. If there were insurmountable differences, knowing of them would be of huge value to the profession and the public, and would in itself provide justification for a broader debate on professionalism.

\section{DENTISTRY AS A BUSINESS}

Dentistry is a profession in healthcare; however, dental practice, where the majority of the profession work, is often perceived as operating more overtly as a business than medicine. This is probably because most patients' are required to pay charges or make co-payments for dental care. Welie, ${ }^{23}$ the ethicist, writing in the Journal of the Canadian Dental Association, has proposed the existence of two models of dentistry, one as a profession, the other as a business. He eloquently argues that these two paradigms are incommensurate and that decisions should be made as to which we are. Currently, the increased demand for improved aesthetics is pushing the dental profession further toward the business model, less helping those in need but more serving those who demand, and can pay.

The 2006 Ethics Summit on Commercialism, ${ }^{24}$ appears to have agreed with Welie's conclusions, ${ }^{11,23,25}$ perceiving the trouble to lie not with the business strategies and techniques adopted by the dental profession, but with the core ideology of self-interest. There is a view, acknowledged within the profession, that the concept of the professional as guardian of a social contract is being displaced by 'the notion of the professional as a purveyor of expert services'. ${ }^{10}$ Is it any surprise therefore that the public will also view the altruistic nature of the dental professional with suspicion?

This is not to say that pursuit of business precludes acting in an unethical manner. Business ethics is a discipline in its own right. It can be defined as 'a system of moral principles applied in the commercial world' where they provide 'guidelines for acceptable behavior by organizations in both their strategy formulation and day-to-day operations' ${ }^{26}$ Pressure from consumers is pushing for more ethical and responsible business practices, with many organisations choosing to make a public commitment to ethical business by formulating codes of conduct and operating principles. ${ }^{26}$

There exist two perspectives on business ethics - namely that of the interests of the shareholder, and the interests of the stakeholder. The former consider their ethics in relation to what makes most money and the latter the need for corporate social responsibility. ${ }^{27}$ People such as Welie suggest that these ends are conflicting, and there cannot be a coexistence of a professional's social contract and the pursuit of business; either one aims to serve others or aims to serve oneself. It is a difficult piece of reasoning to escape.

We propose that the dental profession should not accept this conclusion, and it is an issue we have to resolve. Given that almost $90 \%$ of the dental profession work in general dental practice, are dentists resigned to be no more than ethical business people? If a dentist wishes to do good for people, not much will be done if the practice becomes bankrupt. We cannot escape the fact that if a business mentality were to be ignored totally, dentistry in the UK would rapidly cease to function in both the primary and secondary sectors, whether privately or with the NHS - practices must continue to generate profit and PCTs must balance their books; ${ }^{28}$ it would be unethical if the dental profession did not make an appropriate use of resources, both human and financial. It will otherwise cease to exist; an example of the Kantian categorical imperative, perhaps.

We can then defend a dentist who is both a professional and a business person on the grounds that keeping the business working well is part of the social corporate responsibility to the benefit of all the patients treated there. But at precisely what stage does this argument stop working? As soon as the dentist earns more than a subsistence income? When there is a second Ferrari 


\section{Dental Professionalism?}

Dental professionalism signifies a set of values, behaviours and relationships that underpins the trust the public has in dentists.

Dentistry is a vocation in which a dentist's knowledge, clinical skills, and judgement are put in the service of protecting and restoring oral, dental and social well-being. This purpose is realised through a partnership between patient and dentist, one based on mutual respect, individual responsibility, and appropriate accountability.

In their day-to-day practice, dentists are committed to:

- Integrity

- Compassion

- Altruism

- Continuous improvement

- Excellence

- Working in partnership with members of the wider healthcare team.

These values, which underpin the science and practice of dentistry, form the basis for a moral contract between the profession and society. Each party has a duty to work to strengthen the system of oral and dental healthcare on which our collective dignity depends, within the context of a realistic economic framework that will permit the extension of this system to all those in need both now and in future. Amended definition from RCP, 2005

\section{Fig. 2 Proposed definition of dental professionalism}

parked in front of the practice? The answer is not easy, but it can perhaps be summed up by which we value more: money or patients.

\section{DEFINITION OF DENTAL PROFESSIONALISM}

Would we feel comfortable in taking on board an amended form of the RCP definition? A suggested format can be found in Figure 2. Do we perceive dentistry as a vocation or were we mainly attracted by features of the job? Do we demonstrate integrity, compassion, altruism, continuous improvement, excellence and work in partnership with other members of the wider dental and healthcare team? Do we aspire to this as a professional standard? And, if so, what are the practical implications of such a definition? How can these translate into the business environment of dental care?

\section{CONCLUSION}

The questions raised in this paper are not purely a matter of academic discussion. Our profession continues to move away from autonomy and towards ever more far-reaching regulation as medicine has done, bringing with it a corresponding increase in the role of sanction. Professionalism is a core domain of the imminent revalidation process with which we shall all have to comply - we must make efforts to understand it. The authors suggest that in creating a shared concept of professionalism, we have our best chance of commensurating the needs of our individual patients, the wider population, the needs of the health care teams we lead, and our personal aspirations. A productive debate and clear outcome will go some way to ensuring that the place of ethics is not demeaned in this new environment.

Thus it is our contention that a debate in dentistry as to the meaning and use of professionalism is needed, as already recognised by the medical profession. The framework in which our debate should occur is one in which we put patient interests at the heart of the practice of dentistry, define roles and standards more clearly, strengthen leadership, and explore relationships within and without healthcare. It will allow us to maintain integrity striking the correct balance between the multiple and sometimes conflicting ends we seek, assess the professional potential of new applicants to dentistry, and train accordingly.

1. General Dental Council Revalidation Working Group. Revalidation of dental professionals. London: General Dental Council, 2008.

2. Royal College of Physicians. Doctors in society - medical professionalism in a changing world.
London: Royal College of Physicians, 2005.

3. Rosen B, Dewar S. On being a doctor: redefining medical professionalism for better patient care. London: The King's Fund, 2005.

4. Levenson R D S, Shepard S. Understanding doctors: harnessing professionalism. London: King's Fund, 2008.

5. Blandy J P, Lumley J S P. The Royal College of Surgeons of England: 200 years of history at the millennium. Oxford: Blackwell Science, 2000.

6. Welie J V. Do you have a healthy smile? Med Health Care Philos 1999; 2: 169-180.

7. Health SoSf. Alan Johnson publishes proposals to make more drugs available on the NHS: NHS care will not be withdrawn from patients who choose to pay for additional drugs - 14 November London: Department of Health, 2008.

8. Bertolami C N. Why our ethics curricula don't work. J Dent Educ 2003; 68: 414-425.

9. Garratt F, Varlaam C. Revalidation of dental profes sionals. London: General Dental Council Revalidation Working Group, 2007.

10. Masella R. Renewing professionalism in dental education: overcoming the market environment. J Dent Educ 2007; 71: 205-216.

11. Welie J V. Is dentistry a profession? Part 1. Professionalism defined. J Can Dent Assoc 2004; 70: 529-532.

12. Nath C. Perceptions of professionalism vary most with educational rank and age. J Dent Educ 2005; 70: 825-834.

13. ABIM, ACP-ASIM, EFIM. A Physician Charter: Project of the ABIM Foundation, ACP-ASIM Foundation, and European Federation of Internal Medicine: ABIM Foundation, ACP-ASIM Foundation, and European Federation of Internal Medicine, 2002.

14. Brosky M, Keefer O A, Hodges J S, Pesun I J, Cook G. Patient perceptions of professionalism in dentistry. J Dent Educ 2003; 67: 909-915.

15. Conlon M. Appraisal: the catalyst of personal development. Br Med J 2003; 327: 389-391.

16. West M. How can good performance among doctors be maintained? Br Med J 2002; 325: 669-670.

17. Smith J. Shipman: the final report. London, 2005.

18. Mathewson H. Meeting the standard. Summons, 2007.

19. Mathewson H, Rudkin D. The GDC - lifting the lid. Part 1: professionalism and standards. Br Dent J 2008; 204: 571-574.

20. Crossley M L, Mubarik A. A comparative investigation of dental and medical student's motivation towards career choice. Br Dent J 2002; 193: 471-473

21. Test UCA. The UK Clinical Aptitude Test (UKCAT) for Medical and Dental Degrees. 2008. Available from: http://www.ukcat.ac.uk/

22. Röding K. Professional competence in final-year dental undergraduates: assessment of students admitted by individualised selection and through traditional modes. Eur J Dent Educ 2001; 5: 12-16.

23. Welie J V. Is dentistry a profession? Part 3. Future Challenges. J Can Dent Assoc 2004; 70: 675-678.

24. American College of Dentists, American Dental Association (eds). Ethics Summit on Commercialism. Chicago, Feb 28 - Mar 12006

25. Welie J V. Is dentistry a profession? Part 2. The Hallmarks of Professionalism. J Can Dent Assoc 2004; 70: 599-602.

26. BNet Business Dictionary. Business Ethics: definition. 2008 [updated 2008; cited]; Available from: http://dictionary.bnet.com/definition/ Business+Ethics.html

27. White $M$ G, Sundblad D, Finley A. A definition for business ethics. 2008. Available from: http://business.lovetoknow.com/wiki/A_Definition_for_Business_Ethics

28. Hewitt P. The NHS: the next 10 years. London School of Economics, 14 June 2007. 